\begin{tabular}{|c|c|c|}
\hline 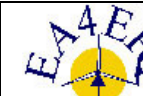 & $\begin{array}{l}\text { European Association for the } \\
\text { Development of Renewable Energies, Environment } \\
\text { and Power Quality (EA4EPQ) }\end{array}$ & $\begin{array}{c}\text { International Conference on Renewable Energies and Power Quality } \\
\text { (ICREPQ'12) } \\
\text { Santiago de Compostela (Spain), 28th to 30th March, } 2012\end{array}$ \\
\hline
\end{tabular}

\title{
Design and Analysis of Brushless Self-Excited Three-Phase Synchronous Generator
}

\author{
M. O. Oliveira ${ }^{1-2}$, A. S. Bretas ${ }^{1}$, F. H. García ${ }^{1}$, L. A. Walantus ${ }^{2}$, H. E. Muñoz ${ }^{2}$, O. E. Perrone ${ }^{2}$ and J. H. Reversat ${ }^{2}$ \\ ${ }^{1}$ Electrical Engineering Department \\ UFRGS, Federal University of Rio Grande do Sul \\ 103 Osvaldo Aranha Avenue, Porto Alegre-RS (Brazil) \\ Phone/Fax number: +55 51 3308-4437, e-mails: moliveira@ece.ufrgs.br, abretas@ece.ufrgs.br, fhdez@ece.ufrgs.br
}

\author{
${ }^{2}$ Energy Study Center to Development -CEED \\ UNaM, National University of Misiones \\ 327 Juan Manuel de Rosas Street, Oberá-Mnes. (Argentina) \\ Phone/Fax number: +54 03755-422170, e-mails: walantus@fio.unam.edu.ar, hmunioz@fio.unam.edu.ar, \\ perrone@fio.unam.edu.ar, hreversat@fio.unam.edu.ar
}

\begin{abstract}
.
This paper presents the main features of design, construction, performance analyses and experimental studies of a brushless self-excited three-phase synchronous generator. The basic construction, principle of operation, and exciting characteristics are described. In proposed machine the rotor winding is shorted through diodes and the self-excitation is reached by a slip between rotor and stator winding built with different pole numbers. Computer simulations performed with MATLAB ${ }^{\circledR}$ software were used to verify the mathematical model of the brushless self-excited synchronous generator and the achieved results showed similar behavior with experimental values.
\end{abstract}

\section{Key words}

Brushless generator, synchronous machine, self-excited system, half-wave rectified, excited capacitor.

\section{Introduction}

Synchronous generators and the associated control system constitute one the most important and complex projects presented in the electric power system. These machines generate electricity which is then transported to consumption center through transmission lines. This generators type is typically projected with the slip rings whose terminals can be used with a steady source power for excitation. The carbon brushes are the most critical parts of the power generator because they demand an important maintenance level, and therefore are preferred than the brushless generators to supply energy to critical loads. The brushless generators usually consist of a permanent magnet to eliminate rotating excitation winding, carbon brushes and slip rings [1].

On the other hand, the small capacity generator works in severe operation conditions, therefore, it is essential that its construction is simpler and robust. Also, self-excitation and self-regulation of voltage in a synchronous generator is important to reduce the maintenance level and the control system complexity in case of large load variations.

In this sense, many project and studies of synchronous generators have been proposed in the last years. Nonaka and Kesamaru [2] described a new brushless generator without exciter rotating where the stator has two independent windings with different pole numbers. The first is the single-phase load winding and the second is the exciter winding in direct current (DC). This generator has the advantage of presenting an almost constant output voltage for large load variations and different speeds. On the same theme, Inoue et al. [3] proposes a novel brushless generator with three-phase armature windings on the stator, one field winding and one exciting winding with five time as many poles of the armature winding on the rotor, and a three-phase reactor connected to the terminal of the armature winding. The disadvantage is the need of an external battery since the capacitors system is not fully efficient. More recently, Chan and Lai analyzed the steady state behavior of a single-phase self-excited generator where the operation equations are derived using the symmetrical component method [4]. Hooke and Jeeves method is used to determine the machine variables. A more detailed discussion of some excitation control systems for brushless synchronous generators is presented in [5]-[7], and different methods of voltage regulation in generators are proposed in [8]-[10].

In this context, the objective of this paper is to present and discuss the results obtained from the modeling, construction and testing of a synchronous generator with asynchronous excitation (SGEA) and with an uncontrolled rectified bridge. On the last, the terminal voltage of the machine is regulated through the field current. The test results obtained with the prototype test are acceptable and encouraging. 


\section{Modelling of the Brushless Self-Excited Synchronous Generator}

Although the field winding of a traditional synchronous generator is in the rotor and the field winding of a homopolar generator is located in the stator, both machines share the same terminal characteristic and can be described with the same parameters grouped [1]. The classic model of separately excited synchronous machines can be represented in rotational coordinate $d-q$ [10]. However, detailed modeling of synchronous generator for transient studies should include a variable phase model, orthogonal $d-q$ axis model and finite element analysis [9], [2].

Fig. 1 shows the basic circuit of the brushless self-excited synchronous generator designed in this work. The stator of this machine has two windings, the load winding $W a$ and the auxiliary self-excitation winding $W c$, connected to a variable capacitor $C$. The rotor has only one field winding $W_{f d}$, shorted with diodes $D$. For a given output frequency $f$, a voltage is induced on the $W_{f d}$ by the reverse field due to the armature reaction. This voltage is then rectified in halfwave to obtain the excitation voltage of the synchronous generator.

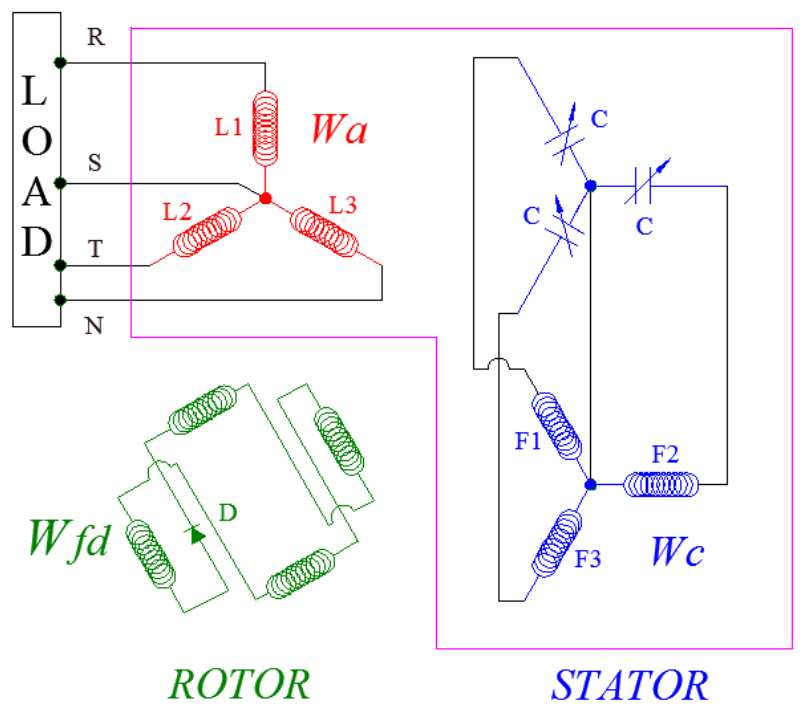

Fig. 1. Electric circuit for brushless self-exciting three-phase synchronous generator.

The basic steady-state equations for modeling the brushless self-excited synchronous generator were obtained from [11]. The following simplifying assumptions were considered:

- Negligible winding mmf (magnetomotive force) and saliency harmonics.

- Rotor cage equivalent to sinusoidally distributed winding on each axis.

- Constant rotor speed.

- Negligible rotor field winding resistance so that field flux is considered constant.

Other important aspects for modeling the brushless self-excited synchronous generator are presented in [12][15].

\section{A. D-q Model for Single Phase Synchronous Machine}

Steady state armature current is given by the following equation [11]:

$$
I_{a}=\sum_{n=1}^{\infty} I_{a n} \cos \left(n \omega_{r} t+\Phi_{a n}\right)
$$

and the exciter winding current has the form:

$$
I_{b}^{\prime}=\sum_{n=1}^{\infty} I_{b n}^{\prime} \cos \left(n \omega_{r} t+\Phi_{b n}\right)
$$

where $I_{a n}, \Phi_{a n}, I_{a n}^{\prime}$, and $\Phi_{b n}$ are unknow.

The temporal and spatial variation of flux linkage between the exciter winding and armature is defined by the following expression:

$$
\left[\begin{array}{l}
\psi_{a} \\
\psi_{b}^{\prime}
\end{array}\right]=\left[\begin{array}{cc}
\cos \left(\omega_{r} t+\delta\right) & \operatorname{sen}\left(\omega_{r} t+\delta\right) \\
-\operatorname{sen}\left(\omega_{r} t+\delta\right) & \cos \left(\omega_{r} t+\delta\right)
\end{array}\right] \times[M]
$$

where the $M$ matrix is defined as:

$$
\left\{\left[\begin{array}{cc}
x_{q} & 0 \\
0 & x_{d}
\end{array}\right]\left[\begin{array}{c}
I_{q}^{r} \\
I_{d}^{r}
\end{array}\right]+\left[\begin{array}{ccc}
-\frac{Z_{m q}^{\prime \prime}}{\omega_{b}} & 0 & 0 \\
0 & \frac{Z_{m d}^{\prime \prime}}{\omega_{b}} & \frac{x_{m d}^{\prime}}{x_{f r}^{\prime}}
\end{array}\right]\left[\begin{array}{l}
\frac{d}{d t} I_{q}^{r} \\
\frac{d}{d t} I_{d}^{r} \\
\psi_{f r}^{\prime}
\end{array}\right]\right\}
$$

where the parameters $x_{q}, x_{d}, Z{ }_{m q}, Z^{\prime}{ }_{m d}, x^{\prime}{ }_{m d} \mathrm{y} x^{\prime}{ }_{f r}$ were calculated as detailed in [11].

The armature winding flux linkage, $\Psi_{a}$, from (3) is substituted into the armature voltage expression:

$$
\frac{d}{d t} \frac{\psi_{a}}{\omega_{b}}+R I_{a}=0
$$

where $R$ is the load resistance.

The exciter winding flux linkage, $\Psi_{b}$, is substituted into the exciter voltage expression:

$$
\frac{d}{d t} \frac{\psi_{b}^{\prime}}{\omega_{b}}+x_{l b s} \frac{d}{d t} I_{b}^{\prime}+r_{b}^{\prime} I_{b}^{\prime}+\omega_{b} X_{c}^{\prime} \int I_{b}^{\prime} d t=0
$$

where $X^{\prime}{ }_{c}$ is the capacitive reactance referred to the armature winding.

According to [11], the resulting equations consist of equations of fundamental frequency and an infinite series of harmonics voltages. The equation of excitation current and armature are given by the following expressions:

$$
\begin{gathered}
I_{b 1}^{\prime} e^{j \Phi_{b 1}}=K_{b 1} \Psi_{f r}^{\prime} e^{j\left(\delta+\gamma_{1}\right)} \\
I_{b n}^{\prime} e^{j \Phi_{b n}}=\pi_{k=3}^{n} K_{b n} I_{b 1} e^{j\left(n \delta+\sum_{k=1}^{n} \phi_{k}\right)} \\
I_{a 1} e^{j \Phi_{a 1}}=K_{a 1} I_{b 1}^{\prime} e^{j\left(\Phi_{b 1}+\alpha_{1}\right)}
\end{gathered}
$$




$$
I_{a n} e^{j \Phi_{a n}}=K_{a n} \pi_{k=3}^{n} K_{b k} I_{b 1} e^{j\left(\Phi_{b n}+\alpha_{n}\right)}
$$

where $K_{b n}, \gamma_{n}, K_{a n}$ and $\alpha_{n}$ are functions of the machine parameters. The load angle, $\delta$, and field flux, $\Psi_{f r}^{\prime}$, are unknowns.

Thus, if the field winding resistance is neglected then and assuming the field diode commutates when time $t=0$, it is possible to obtain:

$$
\begin{gathered}
\left.I_{f r}^{\prime}\right|_{t=0}=\frac{\Psi_{f r}^{\prime}}{x_{f r}^{\prime}}-\frac{x_{m d}}{x_{m d}+x_{l f r}^{\prime}} I_{d}^{r}+\frac{Z_{m d}^{\prime \prime}}{x_{m d}^{\prime}} \frac{d I_{d}^{r}}{d t}=0 \\
\left.e_{f r}^{\prime}\right|_{t=0}=-\frac{x_{m d}}{\omega_{b}} \frac{d I_{d}^{r}}{d t}-\frac{Z_{m d}^{\prime \prime}}{\omega_{b}^{2}} \frac{d^{2} I_{d}^{r}}{d t^{2}}=0 \\
\left.\frac{d e_{f r}^{\prime}}{d t}\right|_{t=0}=-\frac{x_{m d}}{\omega_{b}} \frac{d^{2} I_{d}^{r}}{d t^{2}}-\frac{Z_{m d}^{\prime \prime}}{\omega_{b}^{3}} \frac{d^{3} I_{d}^{r}}{d t^{3}} \geq 0
\end{gathered}
$$

where $I_{f r}^{\prime}$ is the field current and $e_{f r}^{\prime}$ is the field voltage applied across the field diode.

\section{Electric Circuit and Mechanical Structure of the Synchronous Generator Proposed}

The proposed SGEA was built using the mechanical structure of an asynchronous motor of 5HP, $1000 \mathrm{rpm}$. This generator is asynchronously self-excited, ie, the rectified alternating voltage used in the generator excitation is obtained through a slip between the rotor and stator windings. The stator consists of an auxiliary field winding in parallel with a capacitor bank and a stator winding load. The voltage induced in the rotor field winding is one-phase and half-wave rectified.

\section{A. Operating Principle}

Fig. 2 shows the configuration and arrangement of the rotor and stator windings of the proposed synchronous machine.

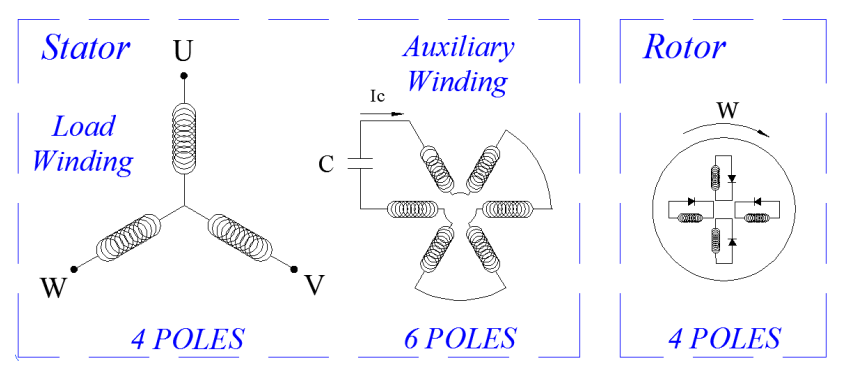

Fig. 2. Stator and rotor winding single-phase configuration.

When the generator starts to turn, it is induced on the single-phase winding an electro-motive force $(\mathrm{fem})$ due to the residual magnetism of the rotor. Thus, a current $I_{C}$ will start flowing in the circuit formed by the parallel between single-phase winding and the capacitor $C$ connected to it. The $I_{C}$ current, known as magnetizing current of self- excitation, is reinforced by the capacitor current once the generator reaches steady state. It is important to recall that a difference exists between the variables related to magnetic fields due to the main field speed (4 poles) is $1500 \mathrm{rpm}$ and auxiliary field speed (6 poles) is $1000 \mathrm{rpm}$. The generator rotation speed is kept stable at $1500 \mathrm{rpm}$ so there is a difference in favor of the excitation current $I_{C}$. The single-phase winding of six poles takes the capacitor the reactive power for excitation and the capacitor size is determined in this design. The field excitation current of the stator $\left(I_{C}\right)$ produces a magnetic field $B$ through the air gap and induces on the rotor winding a new fem responsible for creating the main excitation field.

\section{B. Stator Circuit Characteristics}

The stator consists of the auxiliary and load winding. Both windings have a sinusoidal distribution of magnetic flux in the air gap produced by the stator current of the machine. In this circuit, it is very important the orientation of the magnetic axis between the two windings for the machine work correctly. In this sense, the angle between the magnetic axis of the load winding (power coil) and auxiliary winding (connected to the capacitor bank) should be 90 electrical degrees.

\section{Rotor Circuit Characteristics}

The most appropriated is to make the rotor magnetic flux a uniform distribution along the air gap and a magnetic density $B$ with constant geometric distribution. Thus, as the rotor rotates at a constant speed, the magnetic flux in the generator varies in pulses form with a frequency twice the stator frequency. This variation causes that the turns "see" (or be cut) by a relative flux that varies sinusoidally in space and time.

In practice, the rotor current is not exactly pulsing and sinusoidal. This problem must be compensated by the rotor magnetic circuit shape, for example, changing the polar heads or decreasing the air gap. This situation occurs with the deformation of the excitation circuit current due to the presence of harmonic components.

The generator does not work if there is not a certain residual magnetism in the core. If there is no residual magnetism, the excitation process is not initiated and therefore in this project the residual magnetism is generated by placing small permanent magnets in the polar heads.

\section{Brushless Excitation System}

Excitation systems with DC or AC exciters and rectifiers must be transferred from these facilities to the field winding of the generator, demanding slips rings and brushes. This makes both the design of these devices as their maintenance more difficult, increasing the degree of complexity with the increase of the nominal power of generators. The main problems are related to cooling of the collector rings and the useful life of the brushes. To solve this problem successfully, an excitation system without slip rings was projected. 


\section{E. Rotor Winding Connection}

Fig. 3 shows the connection diagram of the rotor winding. Here, each coil consists of a half-wave rectification circuit, connected (shorted) to a diode rectifier to form alternating poles. These connections are made from the exterior of the rotor winding set, allowing quick and easy implementation to carrying out the corresponding measurements of voltage (V) and current (A). This configuration gives the excitation current which is the main generator field.

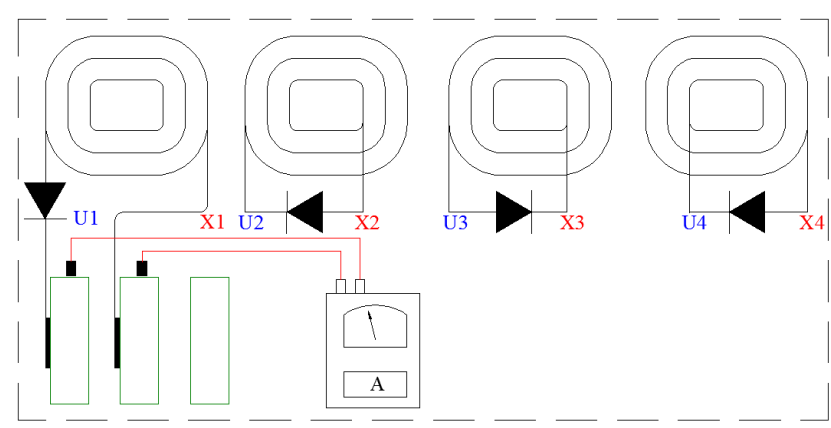

Fig. 3. Connection diagram of the rotor winding.

\section{F. Prototype Construction}

Fig. 4 shows part of the construction process of the prototype brushless self-excited generator. Part (a) presents the adaption process of the slots on the base machine which later enabled the construction of the stator winding (b). It can be observed the mechanic basic design of the rotary rectifier diodes in (c) and its mounting on the rotor in (d). Part (e) shows the stator and rotor winding before final assembly and part (f) presents the connection of brushless self-excitation synchronous generator on the table test.
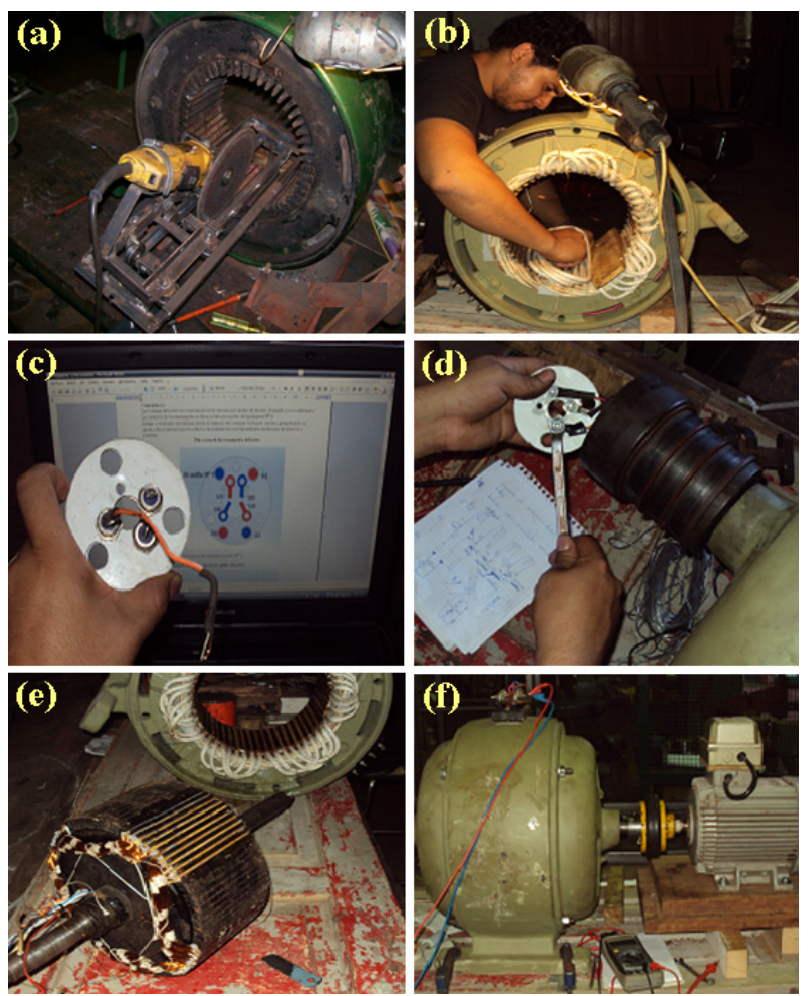

Fig. 4. Prototype construction process.
The asynchronous auxiliary winding is connected in series to form 6 poles in single phase configuration. This winding has a resistance of $33.9 \Omega$.

The polar heads of the inductor winding on the rotor are placed alternately and separated by 10 slots which house the partial side coil, where each coil consists of 60 conductors.

On the other hand, the radial length of the air gap between rotor and stator is $2.5 \mathrm{~mm}$ and the necessary induction on the rotor machine is 1.15 Tesla. The amperes-turns for meter (A-turns/m) necessary to determine the magneto-motive force $(\mathrm{mmf})$ in each circuit of the generator were obtained through the magnetization curve (B-H) of the machine study, obtained through of the laboratory test and shows in the Fig. 5.

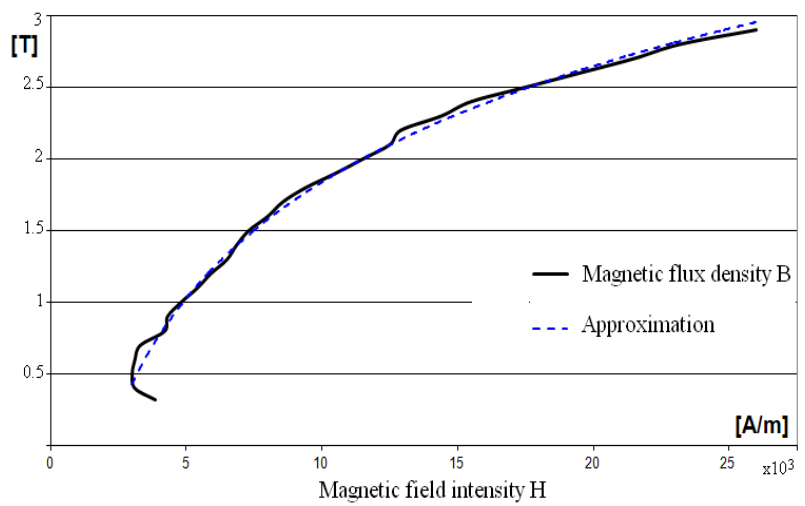

Fig. 5. Magnetization curve $(B-H)$ for generator study.

\section{Test Results and Discussion}

The mathematical model used in computer simulation was implemented in MatLab ${ }^{\circledR}$ environment [16]. Fig. 6 illustrates the rotor winding current behavior (excitation current of machine) before passing through the half-wave rectifier circuit. The capacitor current $I_{C}$ variation, flowing through the auxiliary stator winding it is also shown in this figure.

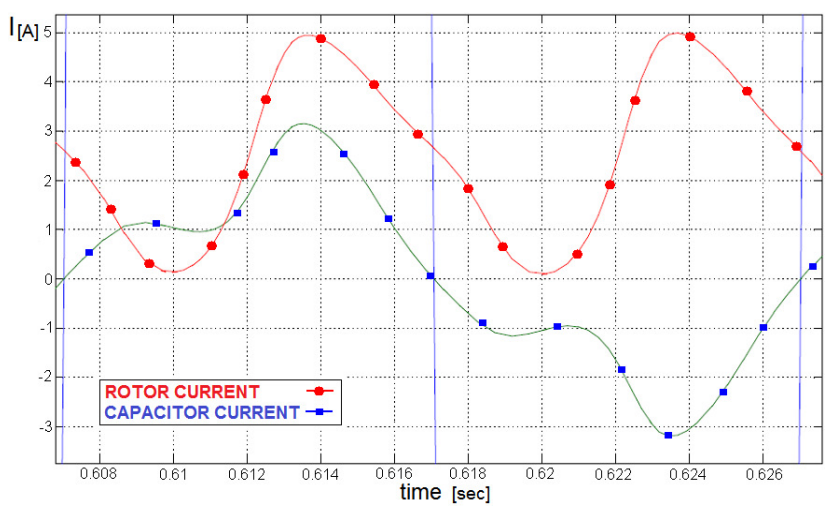

Fig. 6. Temporal variation of the rotor and capacitor currents without load connected on generator.

Fig. 7 shows the temporal variation of the magnetizing inductance of the generator during self-excitation. It is noted that after 0.2 second of simulation, this inductance abruptly decreases in relationship to its initial values 
generating transient deformation on voltage wave of the generator as shown in Fig. 8. It is noted that the voltage wave distortion occurs periodically each $1 / 2$ cycle.

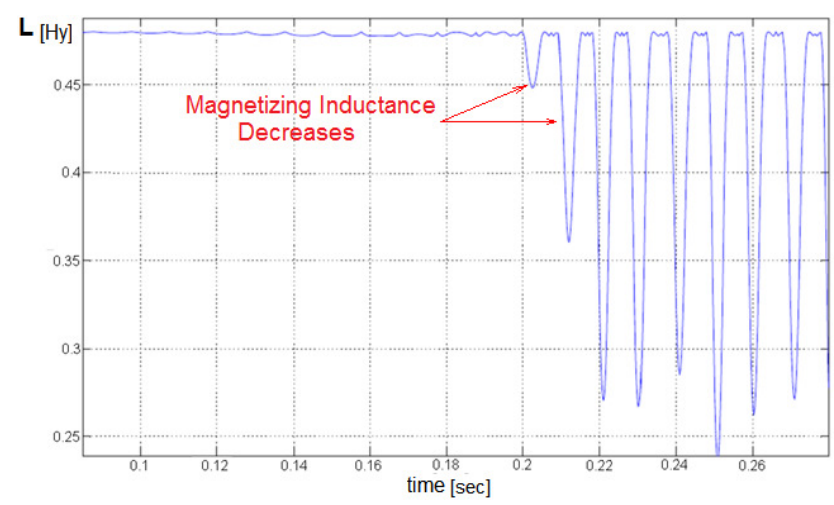

Fig. 7. Temporal variation of magnetizing inductance during selfexcitation of the SGEA.

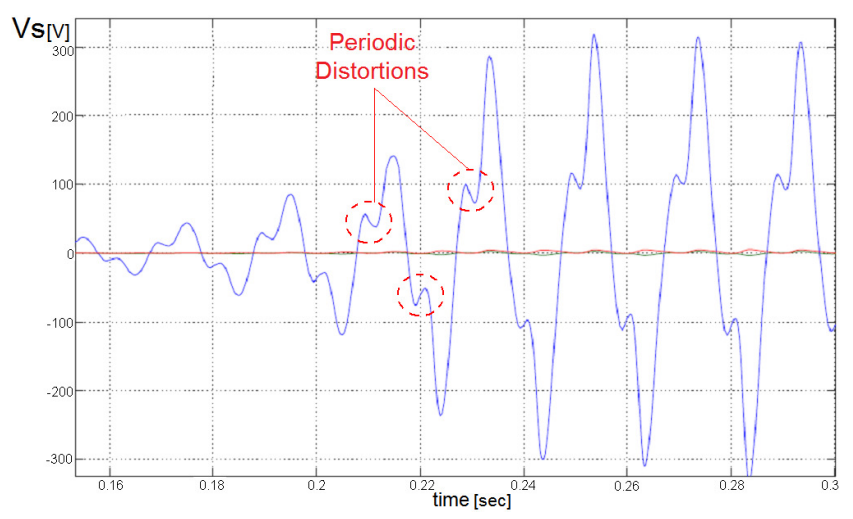

Fig. 8. Temporal variation of single-phase voltage of the generator during self-excitation process with load of $100 \Omega$.

\section{A. Prototype Validation: 4 Pole Machine with Varying of Excitation Voltage}

Table I lists the numerical values for armature voltage as well as voltage and current exciter obtained through tests in laboratory. These values were obtained for 4 pole configuration with $1500 \mathrm{rpm}$.

Table I. - Measurement armature volts for different excited current. (4 poles, $1500 \mathrm{rpm})$

\begin{tabular}{|c|c|c|c|c|}
\hline \multicolumn{2}{|c|}{$\begin{array}{c}\text { Excitation } \\
\text { Parameters }\end{array}$} & \multirow{2}{*}{$\frac{\text { R-phase }}{[\mathrm{V}]}$} & \multirow{2}{*}{$\frac{\text { S-phase }}{[\mathrm{V}]}$} & \multirow{2}{*}{$\frac{\text { T-phase }}{[\mathrm{V}]}$} \\
\hline $\operatorname{Vexc}[\mathrm{V}]$ & $\left(\mathbf{I}_{\text {exc }}\right)[\mathbf{A}]$ & & & \\
\hline 5 & 0.02 & 10 & 11.4 & 13.2 \\
\hline 10 & 0.06 & 19.7 & 22 & 26 \\
\hline 15 & 0.09 & 30 & 32.9 & 39.1 \\
\hline 20 & 0.12 & 40.3 & 43.5 & 51.2 \\
\hline 25 & 0.15 & 51.1 & 55 & 65.2 \\
\hline 30 & 0.19 & 62.2 & 66.2 & 79.3 \\
\hline 35 & 0.22 & 78 & 83.7 & 94.6 \\
\hline 40 & 0.25 & 91 & 97 & 108 \\
\hline
\end{tabular}

Fig. 9 shows a plot of the output armature voltage of the machine vs excitation voltage having an excitation capacitance constant of $100 \mu \mathrm{F}$.

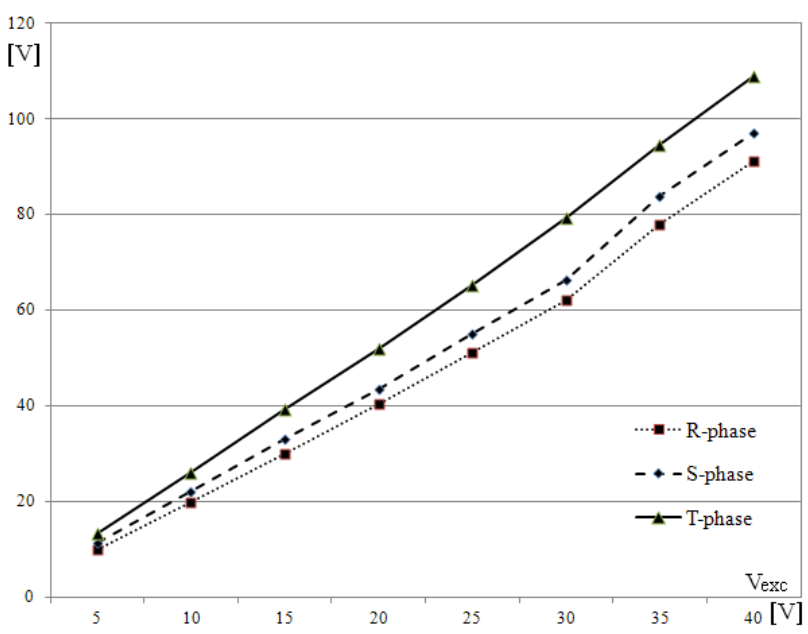

Fig. 9. Armature voltage vs excited voltage for proposed machine with excitation capacitance of $100 \mu \mathrm{F}$ and without load.

Along the self-excitation process, the terminal voltage of the generator changes from transient to steady state reaching a peak value of 320 Volts, as shown in Fig.10. In this figure, it can be observed the deformation caused by the magnetizing inductance variation.

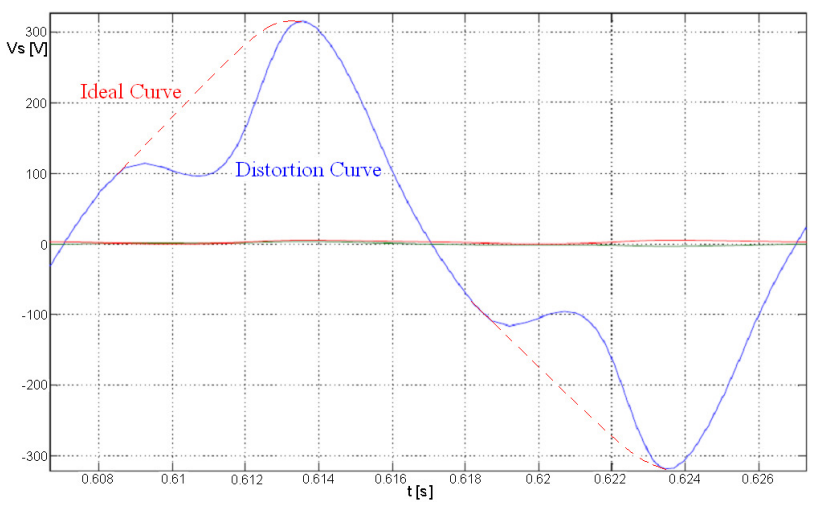

Fig. 10. Temporal variation of the terminal voltage generator.

Fig. 11 shows the temporal variation of the load current of the SGEA to load of 250W.The waveform of this current is similar to the waveform terminal voltage generator, ie, has the same periodic distortions.

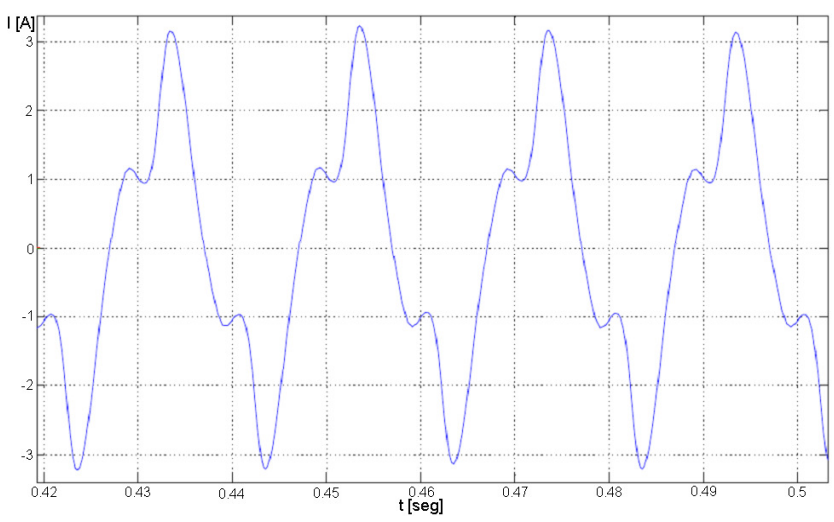

Fig. 11. Temporal variation of the load current to load of $250 \mathrm{~W}$. 


\section{Conclusions}

This paper presents the design, construction and basic analysis of a synchronous generator with brushless asynchronous excitation. The results presented are part of a research project development in the Engineering Faculty of the National University of Misiones, Argentina.

The brushless self-excited three-phase synchronous generator is of simple construction, showing robust and has a low maintenance level mainly because not having slip brushes in the excited system.

The mathematical model used in this study was adequate, since the simulation results were consistent with the experimental results, representing consistently the expected behavior of the generator. In this sense, it was verified that the generator output voltage remained constant for balanced electrical load variation.

Due to the variation of magnetizing inductance during the self-excitation of the generator, fundamental components and other harmonics are generated in the magnetic flux and the rotating field. This results in distorted voltages and currents in the terminal outputs of the generator.

In relation to the mechanical construction, the results related with torque and speed generator were not presented in this paper, however in test development a significant vibration was observed in the structure under load variation condition. On the other hand, steady overheating occurred in the pole pieces leading to a consequent reduction in the life of the machine.

The great difficulty which had to be overcome for the development of the excitation system without brushes was the intensity of centrifugal efforts which rectifier and protection devices would be subject. The use of higher frequencies for AC exciter increased the level of the excitation voltage dramatically improving the efficiency of the system.

\section{Acknowledgment}

The authors thank Engineering Faculty of National University of Misiones for their cooperation in constructing and test of study machine.

\section{References}

[1] E. Akpinar, D. Budakçi, "A model of homopolar sunchronous generator feeding 3-phase brigde rectifier," Department of Electrical and Electronics Engineering Turkey. Available in http://www.emo.org.tr/ekler/30eff1b380505a6_ek.pdf

[2] S. Nonaka and K. Kesamaru, "Analysis of New Brushless Self-Excited Single-Phase Synchronous Generator by Finite Element Method", IEEE Transaction on Industry Application, vol, 30, no. 3, pp. 615-620, May/June 1994.

[3] K. Inoue, H. Yamashita, E. Nakamae, T. Fujikawa, "A Brushless Self-Exciting Three-Phase Synchronous Generator Utilizing the $5^{\text {th }}$ Space Harmonic Component of Magneto Motive Force through Armature Currents", IEEE Transactions on Energy Conversions, vol. 7, no. 3, pp. 517524, September 1992.

[4] T. F. Chan, L. L. Lai, "A Novel Single-Phase SelfRegulated Self-Excited Induction Generator Using a ThreePhase Machine," IEEE Transaction on Energy Conversions, vol. 16, no. 2, June 2001.

[5] A. Godhwani, M. J. Basler, "A Digital Excitation Control System For Use on Brushless Excited Synchronous
Generator," IEEE Transaction on Energy Conversion, vol. 11, no. 3, September 1996.

[6] R. Erceg, G. Erceg, S. Tesnjak, “ Digital excitation system for a small brushlees synchronous generator," Proceeding of the IECON, vol. 1, pp. 97-101, 1997.

[7] R. Erceg, G. Erceg, T. Idzotic, "Using digital signal processor for excitation system of brushless synchronous generator," Proceeding of the IECON, vol. 3, pp. 1355$1360,1999$.

[8] B. Rabelo and W. Hofmann, "Optimal Reactive Power Splitting with Doubly Fed Induction Generator for WindTurbine," Proceeding of DEWEK'2002, CD. Wilhelmshaven, Germany, October, 2002.

[9] Ion Boldea, "The Electric Generators Handbook: Synchronous Generator," CRC Press, vol. 1, Boca Raton FL, 2006.

[10] B. Rabelo, W. Hofmann, M. Tilscher, A. Basteck, "Voltage Regulator for Reactive Power Control on Synchronous Generators in Wind Energy Power Plants," Proceeding of NORPIE, Trondheim, Norway, 2004.

[11] R. M. Cuzner, S. C. Rao, "Validation Study of Mathematical Model for Brushless, Capacitor-Excited Single-Phase Synchronous Generator," Proceeding of Industry Application Conference IAS, vol. 2, pp. 843-849, 1996.

[12] T. Fukami, T. Kondo, T. Miyamoto, "Performance Analysis of a Self-Regulated, Self-Excited, Brushless Three-Phase Synchronous Generator," In Proceeding of IEMD, pp. 89-91, 1999.

[13] S. Nonaka, T. Kawaguchi, "A New Variable-Speed ac Generator System Using a Brushless Self-Excited-Type Synchronous Machine," IEEE Transaction on Industry Application, vol. 28, no. 2, pp. 490-496, March/April 1992.

[14] F. Shibata, T. Kohrin, "A Brushless, Self-Excited Polyphase Synchronous Generator," IEEE Transaction on Power Apparatus and Systems, vol. PAS-02, no. 8, pp. 2413-2419, August 1983.

[15] F. Shibata, N. Naoe, "Characteristics of Brushless and Exciterless, Self-Excited Synchronous Generator," IEEE Industry Application Society Annual Meeting, vol. 1, pp. 293-300, 1990.

[16] The Mathworks Inc. "Mathworks matlab." [On line]. Available in: http://www.mathworks.com/ 